\title{
An Effective Anti-Discoloration Coating for Copper
}

\author{
An-Chou Yeh, Chin-Chuan Huang and Chih-Chen Hsiao \\ Metal Processing R\&D Department, Metal Industries Research \& Development Centre (MIRDC), \\ 1001 Kaonan Highway, Kaohsiung City, Taiwan, R. O. China
}

This article investigated the effectiveness of a newly developed anti-discoloration method for copper (C1100). The procedure involved diffusion of aluminum into the copper substrate and the subsequent formation of $\mathrm{Cu}-\mathrm{Al}$ oxide spinels on the surface by a heat treatment. Samples of $\mathrm{C} 1100$ with and without surface treatment were subjected to ageing at $250^{\circ} \mathrm{C}$ for various length of time up to 40 min in order to promote surface discoloration due to oxidation. In addition, a commercially available anti-discoloration coating (C-107) was applied on testpieces for comparative studies. Tested samples were subjected to spectral colorimeter studies in order to determine the degree of discoloration occurred on the surface; microstructures and phase identifications were examined by SEM and XRD. In conclusions, the newly developed method exhibited potential to protect the surface of C1100, and its performance surpassed that of C-107. [doi:10.2320/matertrans.M2010330]

(Received September 21, 2010; Accepted December 1, 2010; Published January 13, 2011)

Keywords: copper, anti-discoloration, oxidation

\section{Introduction}

The surface of copper can easily develop tarnish, when it is oxidized. ${ }^{1,2)}$ The oxidation of copper involves firstly the formation of $\mathrm{Cu}_{2} \mathrm{O}$, followed by reaction with $\mathrm{O}_{2}$ as temperature increases to form $\mathrm{CuO}$. So, the discoloration of copper surface is associated with the formation of $\mathrm{Cu}_{2} \mathrm{O}$ and $\mathrm{CuO}^{3,4)}$ Copper is widely used as the material for ornaments, and surface protection is required to maintain its surface appearance. There are already several coatings available to protect the copper surface against discoloration to a certain degree, e.g. C-107, which is a BTA (benzotriazole) type solution $\left(\mathrm{C}_{6} \mathrm{H}_{5} \mathrm{~N}_{3}\right.$ base formula $),{ }^{5,6)}$ and ceramic coatings. ${ }^{7)}$ However, ornament manufacturers continue to search for better technique to protect the surface of copper. The aim of present study is to investigate a newly developed antidiscoloration method for copper surface, and compare its performance against a commercial coating C-107.

\section{Experimental Procedure}

In present study, experiments were designed to investigate the discoloration on copper surfaces with and without protections. The samples used in present study were high purity copper $(\mathrm{C} 1100:>99.9$ mass $\% \mathrm{Cu}) ; \mathrm{C} 1100$ plates with dimensions of $50 \times 30 \times 1 \mathrm{~mm}$ were used as testpieces; surfaces of all testpieces were sand-blasted to a roughness of $\mathrm{RA}=0.03 \mu \mathrm{m}$. The testing condition to promote discoloration was set by the actual application temperature (i.e. brazing temperature) in the surrounding of copper ornament, i.e. at $250^{\circ} \mathrm{C}$, and the soak time was up to $40 \mathrm{~min}$. Tested samples were then subjected to spectral colorimeter studies by the BYK-Gardner Color-View System in order to determine the degree of discoloration due to oxidation on the surface. During the measurements, sample surfaces were placed flat against the circumferential illumination plate by a holder. The spectral colorimeter allowed the measurement of the color difference $\Delta E$, which is defined by the international Commission on Illumination (CIE) as the following equation:

$$
\Delta E=\sqrt{\left(\Delta L^{2}+\Delta a^{2}+\Delta b^{2}\right.}
$$

Where $\Delta L, \Delta a$, and $\Delta b$ are color space coordination, $L$ is the luminance, $a$ is ranges from green to red, $b$ is ranges from blue to yellow. The standard testpiece of pale copper color with $(L, a, b)=(65.0,26.9,31.4)$ was used as the reference and scanned by the spectral colorimeter against itself to show a $1 \%$ error for the $\Delta E$ measurements. The value of $\Delta E$ was proportional to the degree of color changes on the surface of C1100; if $\Delta E \leq 2.3$, color difference would be un-noticeable by human eyes. ${ }^{8}$ Each $\Delta E$ presented was an average value of 10 measurements.

To apply the newly developed protection method, firstly a mixture of 0.2 mass $\% / 2 \mu \mathrm{m}$ size aluminum powders in the RMA (Rosin Mildly Activated) flux was prepared. C1100 plates were immersed in $20 \mathrm{vol} \%$ diluted $\mathrm{H}_{2} \mathrm{SO}_{4}$ for $10 \mathrm{~s}$ to reveal bare metal surfaces, then washed by pure water for $20 \mathrm{~s}$ before immersing into this mixture of aluminum powders and RMA flux for $3 \mathrm{~s}$. Samples were then heat treated at $600^{\circ} \mathrm{C}$ for $5 \mathrm{~min}$ with an atmosphere of $5 \mathrm{vol} \%$ hydrogen in Argon, so that $\mathrm{Cu}-\mathrm{Al}$ oxide spinels could be formed on the surfaces. The optimum amount of aluminum powders and the heat treatment temperature were determined experimentally; results indicated 0.2 mass $\%$ aluminum powders and $600^{\circ} \mathrm{C}$ yielded the least $\Delta E(0.88)$. We have found that lower temperatures were not sufficient for aluminum diffusion to form oxide spinels. Higher temperatures actually induced oxidation of the substrate before the formation of oxide spinels. If the content of aluminum powders were below 0.2 mass \%, there were not sufficient $\mathrm{Cu}$ - $\mathrm{Al}$ oxide spinels. On the other hand, excess aluminum powders on the surface yielded color changes. Three sets of samples were prepared for comparative study, (1) C1100 plates with no coating protection, (2) $\mathrm{C} 1100$ plates with $\mathrm{C}-107$ coating on the surface, and (3) $\mathrm{C} 1100$ plates with $\mathrm{Cu}-\mathrm{Al}$ oxide on the surface. The details of the application of C-107 coating had been outlined in a previous study. ${ }^{9)}$ All testpieces with and without protections were aged at $250^{\circ} \mathrm{C}$ for various length of time up to $40 \mathrm{~min}$, then subjected to spectral colorimeter studies. Furthermore, microstructures and phase identifica- 


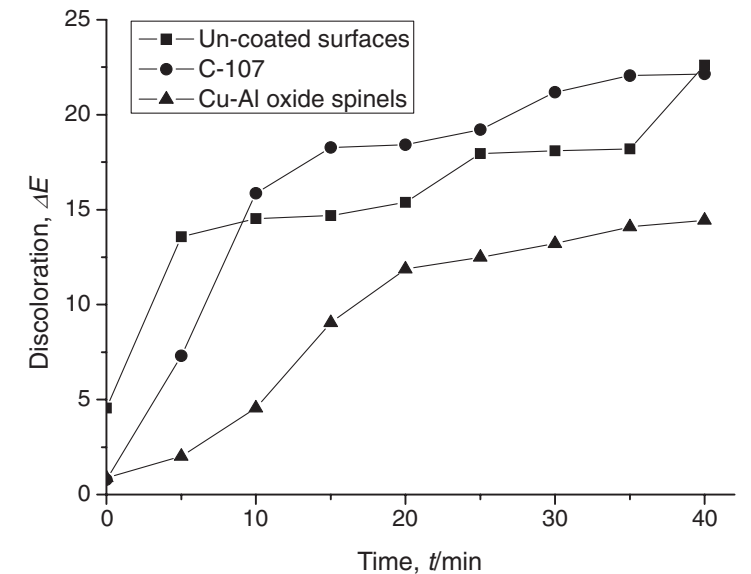

Fig. 1 Spectral colorimeter studies of sample surfaces after aging at $250^{\circ} \mathrm{C}$ for various length of time.
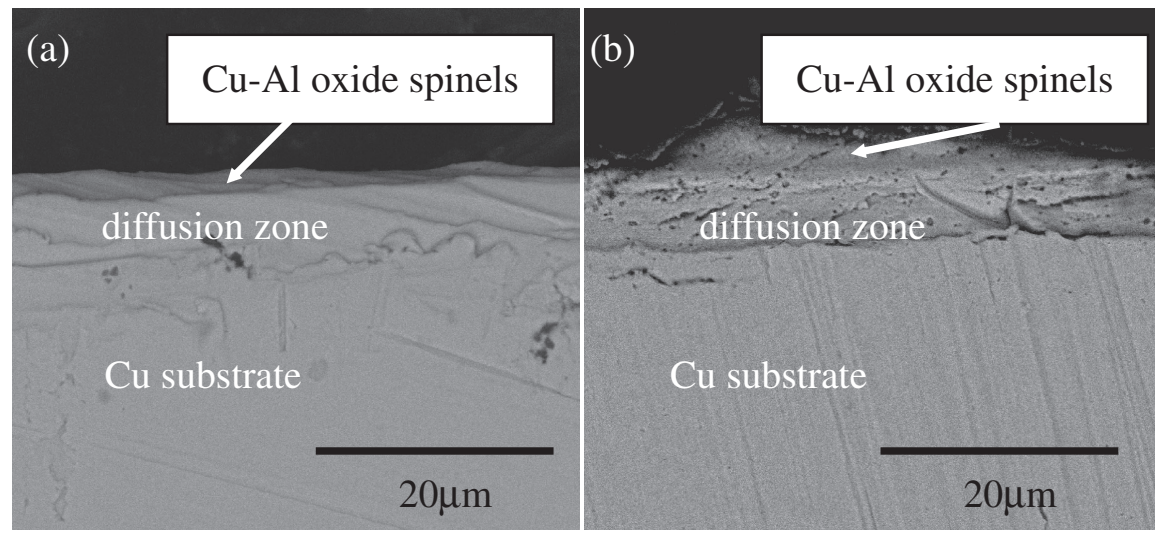

Fig. 3 SEM microstructure observation of the cross-section of the $\mathrm{C} 1100$ sample with $\mathrm{Cu}-\mathrm{Al}$ oxide spinels on the surface. (a) an edge area, (b) a central area.

tions for the surface, which contained $\mathrm{Cu}-\mathrm{Al}$ oxide spinels, were examined by a Hitachi-4700 HORIBA FE-SEM and a PANalytical X'PERT PRO XRD.

\section{Results and Discussions}

The technique developed in this article exhibits impressive ability to protect the surface of copper against discoloration at $250^{\circ} \mathrm{C}$ (Fig. 1). The $\Delta E$ for $\mathrm{C} 1100$ without coating protection evolves from 13.58 ( $5 \mathrm{~min}$ exposure) to 22.61 (40 min exposure); for the $\mathrm{C} 1100$ with $\mathrm{C}-107$ coating, the $\Delta E$ value increases from 7.31 ( $5 \mathrm{~min}$ exposure) to 22.15 (40 min exposure); for the testpieces protected by the new technique, $\Delta E$ is 2.01 after $5 \mathrm{~min}$ exposure and is gradually increased to 14.44 after $40 \mathrm{~min}$ exposure. Figure 1 shows that $\mathrm{C}-107$ can not provide sufficient discoloration protection for $\mathrm{C} 1100$ at $250^{\circ} \mathrm{C}$. By contrast, formation of $\mathrm{Cu}-\mathrm{Al}$ oxide spinels on the surfaces of $\mathrm{C} 1100$ can inhibit surface discolorations. This newly developed technique uses RMA flux to protect the copper surface during the $600^{\circ} \mathrm{C}$ heat treatment, so the aluminum can diffuse into the copper substrate and form $\mathrm{Cu}-\mathrm{Al}$ oxide spinels under the controlled atmosphere. Figure 2 shows results of XRD analysis of a C1100 sample with $\mathrm{Cu}-\mathrm{Al}$ oxide spinels on the surface,

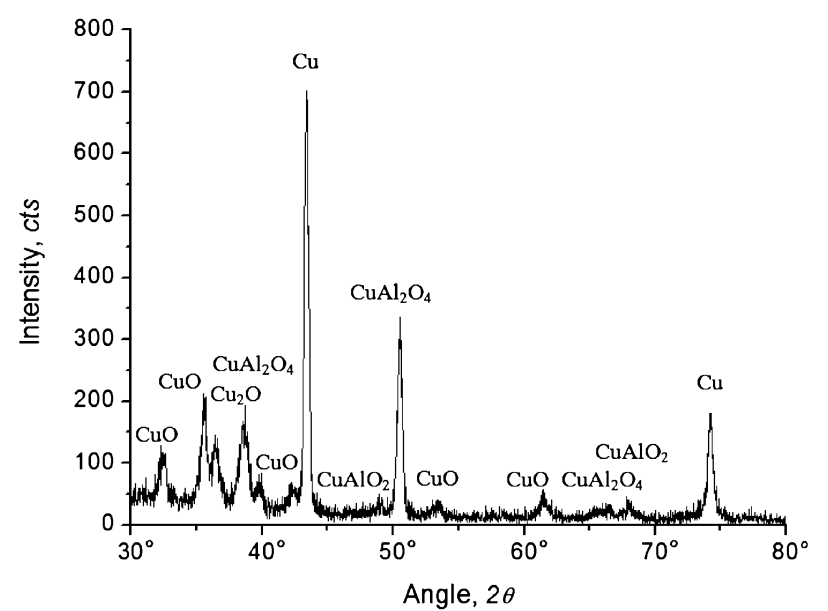

Fig. 2 XRD analysis of a $\mathrm{C} 1100$ sample with $\mathrm{Cu}-\mathrm{Al}$ oxide spinels on the surface. 


\section{Conclusions}

The present study shows a method to form $\mathrm{Cu}-\mathrm{Al}$ oxide spinels on the surface of $\mathrm{C} 1100$, so that its surfaces can be protected against discoloration. The processing procedure is relatively cheap and straightforward. Most importantly, the $\mathrm{Cu}-\mathrm{Al}$ oxide spinels exhibited potential to protect the surface of $\mathrm{C} 1100$ against discoloration at $250^{\circ} \mathrm{C}$.

\section{Acknowledgement}

Authors acknowledge financial supports given by the ministry of economic affairs, R.O.C., department of industrial technology.

\section{REFERENCES}

1) H. F. Zhu: Sci. Conserv. Archaeol. 12 (2000) 9-14.

2) L. W. Zahner: Architectural Metal Surfaces, (Wiley Publish, ISBN 0471263354, December 6, 2004) p28-33.

3) R. B. Faltermeier: Studies in Conservation 44 (1998) 121-128.

4) X. Jin and X. Chen: Corros. Protection 21 (2000) 441-443.

5) W. H. Pu, H. Y. Zhu, F. Zhang and J. D. Zhang: Corros. Protection 26 (2000) 259-260.

6) C. M. Lai: Nonferrous Metals Process 36 (2007) 33-35.

7) I. Kawakatsu, M. Abe and K. Kawakatsu: J. Japan Copper Brass Res. Assoc. 38 (1999) 249-256.

8) G. Sharma: Digital color imaging handbook, (CRC press. ISBN 084930900X, December 23, 2002).

9) C. C. Huang, C. F. Kuo, M. H. Chiang, A. C. Yeh and C. C. Hsiao: Mater. Trans. 50 (2009) 1905-1907. 